\title{
Homocysteine injures vascular endothelial cells by inhibiting mitochondrial activity
}

\author{
FENGYONG YANG $^{1}$, XIUJING $^{1}{ }^{1}$, ZHENG GAO $^{1}$, XINGJU YANG $^{1}$, \\ XINGFENG ZHENG ${ }^{2}$, CHONGHAO DUAN ${ }^{1}$ and JIAN ZHENG ${ }^{3}$ \\ ${ }^{1}$ Intensive Care Unit, The People's Hospital of Laiwu, Laiwu, Shandong 271199; \\ ${ }^{2}$ Burn Center, Shanghai Hospital, Second Military Medical University, Shanghai 200433; \\ ${ }^{3}$ Department of Thoracic Surgery, The People's Hospital of Laicheng, Laiwu, Shandong 271199, P.R. China
}

Received February 6, 2015; Accepted May 9, 2016

DOI: $10.3892 / \mathrm{etm} .2016 .3564$

\begin{abstract}
The aim of the present study was to investigate the role of homocysteine (Hcy) in the pathogenesis of pulmonary embolism (PE) and the associated molecular mechanisms in human umbilical vein endothelial cells (HUVECs). Hcy contents were detected with high-performance liquid chromatography. Apoptosis was detected by flow cytometry using Annexin-V staining. Cytochrome $c$ oxidase (COX) activity was assessed with an enzyme activity assay, and the expression levels of COX 17 were determined by western blot analysis. Intracellular reactive oxygen species levels were measured using a microplate reader with a fluorescence probe. The results demonstrated that, compared with the control group, the serum Hcy levels were significantly elevated in the PE group, suggesting that Hcy may be an indicator for PE. Following treatment with Hcy, the apoptosis rate was markedly elevated in HUVECs. Moreover, Hcy decreased COX activity and downregulated the expression of COX 17 in HUVECs. Furthermore, Hcy increased the ROS levels in these endothelial cells. However, all the above-mentioned physiopathological changes induced by Hcy in HUVECs could be restored by folic acid. In conclusion, the results of the present study demonstrated that Hcy inhibited COX activity, downregulated COX 17 expression, increased intracellular ROS levels and enhanced apoptosis in endothelial cells.
\end{abstract}

\section{Introduction}

Pulmonary embolism (PE) is a frequent clinical syndrome with abnormal pulmonary circulation, which is predominantly caused by the blockage of pulmonary and/or bronchial

Correspondence to: Dr Jian Zheng, Department of Thoracic Surgery, The People's Hospital of Laicheng, 79 Fengcheng West Road, Laiwu, Shandong 271199, P.R. China

E-mail:wgc444@126.com

Key words: pulmonary embolism, homocysteine, vascular endothelial cells, cytochrome $c$ oxidase, apoptosis arteries by thrombus shedding (1). Due to the sudden disease onset, $\mathrm{PE}$ is difficult to treat and usually results in the patient succumbing to the disease $(2,3)$. Homocysteine (Hcy) is an intermediate product of methionine metabolism, and is an independent risk factor for cardiovascular diseases $(4,5)$. Previous studies reported that serum Hcy levels are markedly elevated in patients with PE, which is implicated in the disease pathogenesis (6-8).

Vessel wall injury is one of the important factors for $\mathrm{PE}$, as the pathological changes in endothelial cells may result in the formation of thrombosis $(9,10)$. It has been demonstrated that high concentrations of Hcy induce apoptosis in endothelial cells $(11,12)$, in which mitochondria are involved. Cytochrome $c$ oxidase (COX) is a key enzyme in mitochondrial function (13-15). Enhanced COX activity may increase intracellular reactive oxygen species (ROS) levels, resulting in cellular apoptosis (16-21). Based on these reports, it would be of interest to define the association between Hcy, COX, and ROS in apoptosis, specifically in the context of PE pathogenesis.

In the present study, the effects of Hcy on endothelial cells and the associated molecular mechanisms were investigated.

\section{Materials and methods}

Patients. A total of 10 patients with PE, 4 males and 6 females, aged 50-67 years (with an average age of 60.4 years), were included in this study. These PE cases were diagnosed based on the clinical manifestations and the results from radiological and laboratory tests, in line with the standard literature (22). Furthermore, a further 30 healthy subjects, 15 males and 15 females, aged 30-88 years (with an average age of 56.5 years), were used as the control group. All subjects were recruited from the Laiwu City People's Hospital (Laiwu, China). Prior written and informed consent was obtained from each patient and the study was approved by the ethics review board of the Laiwu City People's Hospital.

Measurement of Hcy concentration. Blood samples were obtained from the PE patients and control subjects, and the concentration of Hcy was measured. Firstly, the column was washed with $95 \%$ methanol for $30 \mathrm{~min}$, followed by $5 \%$ 
methanol for $30 \mathrm{~min}$. The column was then equilibrated with the mobile phase, $0.05 \mathrm{M} \mathrm{KH}_{2} \mathrm{PO}_{4}$ ( $\mathrm{pH}$ 2.1):acetonitrile (93:7). For fluorescence detection, the excitation wavelength was set as $385 \mathrm{~nm}$, and the emission wavelength was set as $515 \mathrm{~nm}$. A $10 \mu \mathrm{l}$ sample was injected, with a detection duration of $10 \mathrm{~min}$. The concentration was calculated using the peak area as the response value, and the results were normalized with the total protein concentration in cardiomyocytes.

Cell culture. Human umbilical vein endothelial cells (HUVECs) were obtained from Beijing Yuhengfeng Biotech (Beijing, China). The cells were cultured in Endothelial Cell Medium (Beijing Yuhengfeng Biotech) supplemented with $10 \%$ fetal bovine serum (FBS; Gibco; Thermo Fisher Scientific, Inc., Waltham, MA, USA) at $37^{\circ} \mathrm{C}$ in an incubator containing $5 \% \mathrm{CO}_{2}$. The control group was free from intervention; the folic acid group was treated with $100 \mu \mathrm{mol} / \mathrm{l}$ folic acid; the Hcy group was treated with $1 \mathrm{mM} \mathrm{Hcy}$; and the Hcy + folic acid group was treated with $1 \mathrm{mM}$ Hcy and $100 \mu \mathrm{mol} / 1$ folic acid.

High-performance liquid chromatography (HPLC). Hcy concentration was determined with HPLC. For serum sample preparation, anticoagulant blood $(10 \mathrm{ml})$ was centrifuged at $200 \mathrm{x} \mathrm{g}$ at $4^{\circ} \mathrm{C}$ for $15 \mathrm{~min}$, and the supernatant was used for measurement. For cell sample preparation, the cells were collected and washed with phosphate-buffered saline (PBS). Following the addition of $100 \mu 11 \%$ sodium dodecyl sulfate (SDS), the cells were lysed with an ultrasonic cell disruptor, and centrifuged at $12,000 \times \mathrm{g}$ at $4^{\circ} \mathrm{C}$ for $10 \mathrm{~min}$, and the supernatant was used for measurement. Prior to the measurements, protein concentrations were determined using a BCA kit (cat. no. BCA1; Sigma-Aldrich, St. Louis, MO, USA). Standard substance concentration series were set as $3.125,6.25,12.5,25,50$, and $100 \mu \mathrm{M}$. For HPLC detection, $10 \mu \mathrm{l}$ tris (2-carboxyethyl) phosphine (Bio-Rad Laboratories, Inc., Hercules, CA, USA) was added into $90 \mu$ protein sample, followed by vortex for $1 \mathrm{~min}$ and incubation at $4{ }^{\circ} \mathrm{C}$ for $30 \mathrm{~min}$. Subsequently, $100 \mu \mathrm{l}$ methanol was added, and the sample was vortexed for $1 \mathrm{~min}$ and centrifuged at 20,000 x g for $10 \mathrm{~min}$. A total of $150 \mu \mathrm{l}$ supernatant was collected into an EP tube, and $20 \mu 11.55 \mathrm{M} \mathrm{NaOH}, 250 \mu \mathrm{l}$ borate buffer (containing $0.125 \mathrm{M} \mathrm{H}_{3} \mathrm{BO}_{3}$ and $4 \mathrm{mM}$ ethylenediaminetetraacetic acid, $\mathrm{pH} 9.5)$, and $10 \mu \mathrm{l} \mathrm{SBD}-\mathrm{F}(10 \mathrm{mg} / \mathrm{ml}$ in borate buffer; Sigma-Aldrich) were added to the sample prior to vortex for $1 \mathrm{~min}$ and incubation at $60^{\circ} \mathrm{C}$ for $60 \mathrm{~min}$. Following centrifugation at $10,000 \mathrm{rpm}$ for $10 \mathrm{~min}, 200 \mu \mathrm{l}$ supernatant was collected and subjected to HPLC detection.

Flow cytometry. Cellular apoptosis was detected by flow cytometry and Annexin-V staining. HUVECs were first incubated with Hcy at $0,0.01,0.1$, and $1 \mathrm{mM}$, respectively, for $24 \mathrm{~h}$. The cells $\left(3 \times 10^{6}\right.$ cells $)$ were then trypsinized, and collected through centrifugation at $200 \mathrm{x}$ g at $4^{\circ} \mathrm{C}$ for $5 \mathrm{~min}$. Following washing with PBS, the cells were incubated with $100 \mu 1$ Annexin-V-FLUOS reagent (Roche Molecular Systems, Inc., Branchburg, NJ, USA) supplemented with $2 \%$ propidium iodide (PI) at room temperature for 10-15 min, and the fluorescence was detected by flow cytometry (FACScan; BS Biosciences, Franklin Lakes, NJ, USA). The apoptosis rate was calculated as the percentage of Annexin-V and PI double positive cells out of the total cells. Experiments were repeated in triplicate.

Mitochondrial isolation. Cardiomyocytes $\left(2.5 \times 10^{6}\right.$ cells; purchased from Dashou Biotechnology Company, Chengdu, China), obtained from heart tissues in rats within 3 days of birth, were cultured in T-25 flasks at $37^{\circ} \mathrm{C}$ for 5 days containing Hepes-buffered Dulbecco's modified Eagle's medium (Gibco; Thermo Fisher Scientific, Inc.) with $10 \%$ FBS. The cells were then digested with trypsin and collected into EP tubes. A total of $1 \mathrm{ml}$ mitochondrial separation medium buffer (containing $0.21 \mathrm{M}$ mannitol, $0.07 \mathrm{M}$ sucrose, $10 \mathrm{mM}$ Tris base and $1 \mathrm{mM}$ EGTA; pH 7.4) was added to re-suspend the cells, and the cell suspension was homogenized 200 times in a Dounce homogenizer (Active Motif, San Diego, CA, USA) on ice. Cell homogenates were transferred into a new $2 \mathrm{ml}$ EP tube, and centrifuged at $600 \mathrm{x}$ g for $5 \mathrm{~min}$ at $4^{\circ} \mathrm{C}$. The supernatant was collected into an $1.5 \mathrm{ml} \mathrm{EP}$ tube, and centrifuged at $1,000 \mathrm{x} \mathrm{g}$ for $5 \mathrm{~min}$ at $4^{\circ} \mathrm{C}$. Subsequently, the supernatant was collected into another $1.5 \mathrm{ml} \mathrm{EP}$ tube, and subjected to centrifugation at $7,000 \mathrm{x} \mathrm{g}$ for $10 \mathrm{~min}$ at $4^{\circ} \mathrm{C}$. This time, the supernatant was discarded, and $1 \mathrm{ml}$ mitochondrial separation medium buffer was used to re-suspend the precipitate, followed by centrifugation at $7,000 \mathrm{x}$ for $10 \mathrm{~min}$ at $4^{\circ} \mathrm{C}$. The supernatant was then discarded, and the precipitate was re-suspended with $1 \mathrm{ml} \mathrm{MSTE}$. Following centrifugation at 10,000 x $\mathrm{g}$ for $10 \mathrm{~min}$ at $4^{\circ} \mathrm{C}$, the mitochondria were obtained.

COX activity assay. A total of $40 \mu 11 \%$ SDS was added into the mitochondria in the EP tube on ice. Following vortexing 6 times within $30 \mathrm{~min}$, the mitochondria were centrifuged at $12,000 \mathrm{x} \mathrm{g}$ for $10 \mathrm{~min}$ at $4^{\circ} \mathrm{C}$. The supernatant was collected into a new EP tube and contained the mitochondrial proteins. The protein concentration was determined using the DAC protein assay reagent (Bio-Rad Laboratories, Inc.), and the standard curve was obtained with bovine serum albumin in $1 \%$ SDS. COX activity was determined with a COX activity assay kit (cat. no. GMS100014.3.1; Shanghai Genmed Gene Pharmaceutical Technology Co., Ltd., Shanghai, China), according to the manufacturer's protocol.

Intracellular ROS level measurement. The cells ( $2 \times 10^{6}$ cells) were trypsinized and collected by centrifugation at $300 \mathrm{x}$ g at $4^{\circ} \mathrm{C}$ for $5 \mathrm{~min}$. An intracellular ROS red fluorescence determination kit (cat. no. GMS10111.1; Shanghai Genmed Gene Pharmaceutical Technology Co., Ltd.) was used to stain the cells. Fluorescence was detected using a microplate reader (iMark; Bio-Rad Laboratories, Inc.), with an excitation wavelength of $540 \mathrm{~nm}$ and an emission wavelength of $590 \mathrm{~nm}$. The intracellular ROS levels were expressed as relative fluorescence unit values.

Western blot analysis. Protein expression levels were assessed by western blot analysis. Total proteins were extracted with a lysis buffer (Sigma-Aldrich). The protein concentration was measured with a DAC protein assay reagent. A total of $30 \mu \mathrm{g}$ protein sample was separated by $12 \%$ SDS-PAGE, and then transferred onto the polyvinylidene difluoride (PVDF) membrane. The membrane was blocked with non-fat milk 
at room temperature for $1 \mathrm{~h}$. Subsequently, goat anti-rat COX 17 primary polyclonal antibody (1:1,000 dilution; cat. no. sc-27533; Santa Cruz Biotechnology, Inc., Dallas, TX, USA) was added to the membrane at incubated at $4^{\circ} \mathrm{C}$ overnight. The secondary horseradish peroxidase-labeled rabbit anti-goat immunoglobulin G (1:2,000 dilution; cat. no. A0208; Beyotime Institute of Biotechnology, Haimen, China) antibody was then added for incubation at room temperature for 1 h. Expression levels were quantified using Quantity One software (version 4.62; Bio-Rad Laboratories, Inc.). GAPDH was used as the internal reference.

Statistical analysis. Data were expressed as means \pm standard deviation. SPSS 13.0 software (SPSS, Inc., Chicago, IL, USA) was used for the statistical analyses. A t-test was performed for the group comparison. $\mathrm{P}<0.05$ was considered to indicate a statistically significant result.

\section{Results}

Serum Hcy levels were elevated in patients with $P E$. The serum Hcy levels were determined in patients with PE and healthy controls. The results obtained from the HPLC demonstrated that, compared with the control group, the serum Hcy levels were significantly elevated in the PE group $(\mathrm{P}<0.05$; Fig. 1$)$. These results suggest that the serum Hcy levels may be an indicator for PE.

Hcy induces apoptosis in endothelial cells. The effects of Hcy on apoptosis in endothelial cells were subsequently investigated. HUVECs were first incubated with Hcy at indicated concentrations $(0,0.01,0.1$ and $1 \mathrm{mM})$ for $24 \mathrm{~h}$, and then the apoptotic rates were detected by flow cytometry. Compared with the control group, treatment with $0.01 \mathrm{mM}$ Hcy marginally increased the apoptosis rate in HUVECs ( $\mathrm{P}>0.05$; Fig. 2). Furthermore, at concentrations of 0.1 and $1 \mathrm{mM}$, Hcy significantly increased the apoptosis rate in HUVECs, compared with the control group ( $\mathrm{P}<0.05$; Fig. 2$)$. These results suggest that Hcy may induce apoptosis in HUVECs, which may contribute to the pathogenesis of PE.

Hcy decreases COX activity and inhibits COX 17 expression. To investigate the effects of Hcy on COX activity levels in endothelial cells, HUVECs were first treated with Hcy $(0,0.01,0.1$, and $1 \mathrm{mM})$ for $24 \mathrm{~h}$, and then COX activity was assessed using the COX activity assay kit. Compared with the control group, Hcy decreased COX activity levels in HUVECs (for $0.01 \mathrm{mM}, \mathrm{P}>0.05$; for 0.1 and $1 \mathrm{mM}, \mathrm{P}<0.05$; Fig. $3 \mathrm{~A}$ ). In addition, the expression levels of COX 17 in these cells were detected by western blot analysis. As shown in Fig. 3B, $0.01 \mathrm{mM}$ Hcy marginally decreased the protein expression levels of COX 17, whereas 0.1 and $1 \mathrm{mM}$ Hcy significantly decreased the expression levels of COX $17(\mathrm{P}<0.05)$. These results suggest that Hcy could decrease COX activity and inhibit COX 17 expression in endothelial cells.

Hcy increases intracellular ROS levels in endothelial cells. The effects of Hcy on the intracellular ROS levels in endothelial cells were then investigated. HUVECs were incubated with $0,0.01,0.1$, and $1 \mathrm{mM} \mathrm{Hcy}$ for $24 \mathrm{~h}$, and the intracellular

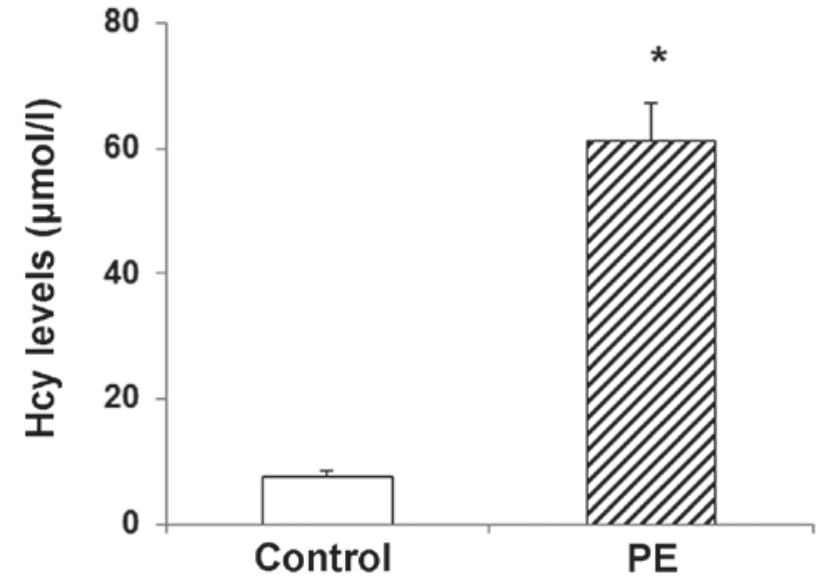

Figure 1. Serum Hcy levels are elevated in patients with PE. The serum Hcy levels were determined in the control and PE groups using high-performance liquid chromatography. ${ }^{*} \mathrm{P}<0.05$, vs. the control group. Hcy, homocysteine; PE, pulmonary embolism.

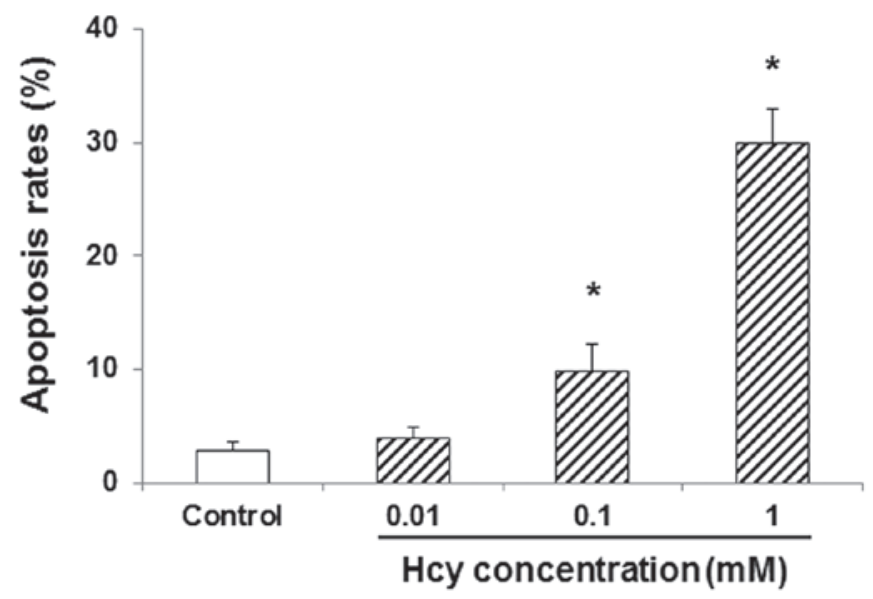

Figure 2. Hcy induces apoptosis in HUVECs. HUVECs were first incubated with Hcy at $0,0.01,0.1$, and $1 \mathrm{mM}$ for $24 \mathrm{~h}$. The apoptotic levels were then assessed sby flow cytometry with Annexin-V staining, and the apoptosis rates were calculated accordingly. ${ }^{*} \mathrm{P}<0.05$, vs. the control group. Hcy, homocysteine; HUVECs, human umbilical vein endothelial cells.

ROS levels were determined. Compared with the control group, $0.01 \mathrm{mM}$ Hcy marginally increased the intracellular ROS levels in HUVECs (P>0.05; Fig. 4). Furthermore, 0.1 and $1 \mathrm{mM}$ Hcy significantly elevated the intracellular ROS levels in these cells $(\mathrm{P}<0.05$; Fig. 4). These results suggest that Hcy could increase the intracellular ROS levels in endothelial cells, which may be associated with its effects on apoptosis in these cells.

Folic acid alleviates the physiopathological changes induced by Hcy. The effects of folic acid on Hcy-induced pathological changes in endothelial cells were then investigated. HUVECs were treated with Hcy and/or folic acid for $24 \mathrm{~h}$, and then the apoptosis levels, the COX activity and COX 17 expression levels, and the intracellular ROS levels were evaluated. Compared with the control group, folic acid treatment alone did not alter the apoptosis rate, COX activity and COX 17 expression, or the intracellular ROC levels in HUVECs (P>0.05; Fig. 5). However, treatment with folic 
A

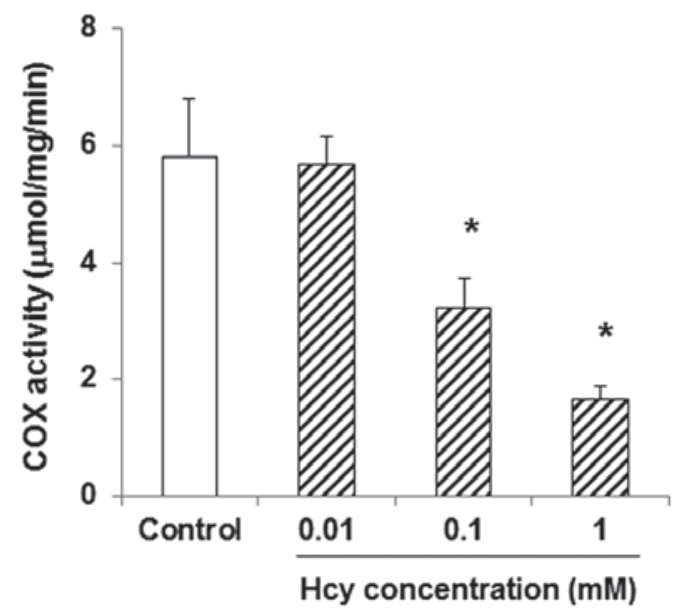

B

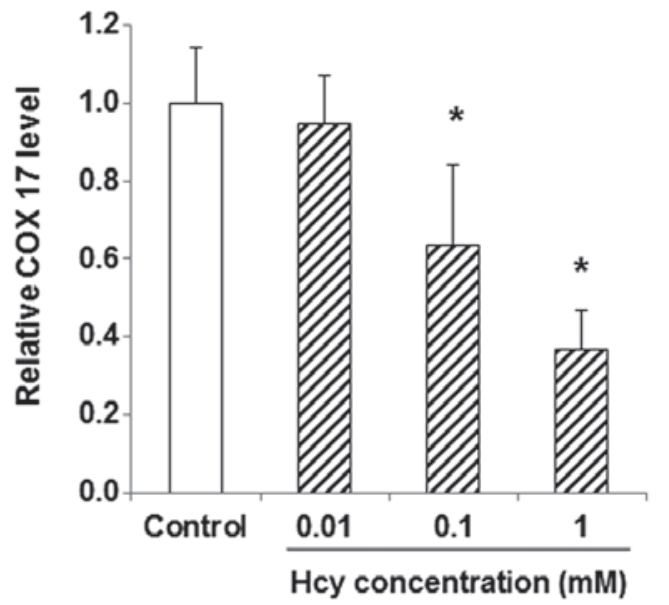

Figure 3. Hcy decreases COX activity and COX 17 expression levels in HUVECs. HUVECs were treated with Hcy at 0, 0.01, 0.1, and $1 \mathrm{mM}$ for $24 \mathrm{~h}$. (A) COX activity was assessed using a COX activity assay kit. (B) The protein expression levels of COX 17 were detected by western blot analysis. "P $<0.05$, vs. the control group. COX, cytochrome $c$ oxidase; Hcy, homocysteine; HUVECs, human umbilical vein endothelial cells.

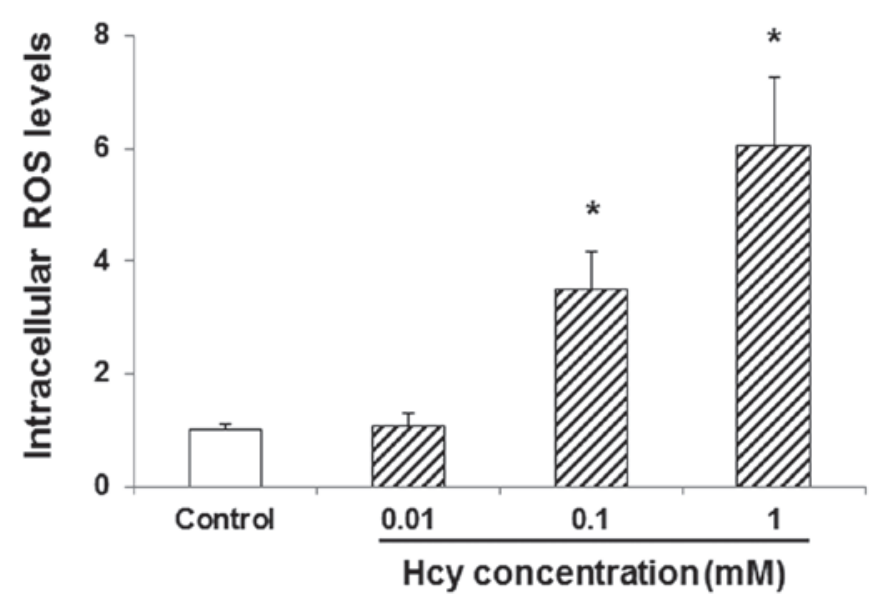

Figure 4. Hcy increases the intracellular ROS levels in HUVECs. HUVECs were incubated with $0,0.01,0.1$ and $1 \mathrm{mM}$ Hcy for $24 \mathrm{~h}$. The intracellular ROS levels were then determined. "P<0.05, vs. the control group. ROS, reactive oxygen species; Hcy, homocysteine; HUVECs, human umbilical vein endothelial cells.

acid inhibited the effects of Hcy in these cells. Compared with the Hcy group, folic acid treatment significantly decreased the apoptosis rate, inhibited the Hcy-induced COX activity decline and COX 17 expression downregulation, and decreased intracellular ROS levels in HUVECs $(\mathrm{P}<0.05$; Fig. 5). These results suggest that folic acid could alleviate the physiopathological changes induced by Hcy in endothelial cells.

\section{Discussion}

PE is an acute pathological syndrome with a relatively high mortality $(2,3)$. It has been reported that the serum Hcy levels are elevated in patients with $\mathrm{PE}$, which is an independent risk factor for cardiovascular diseases, and is an important factor for the occurrence of PE (4-8). In the present study, the effects of Hcy on PE pathogenesis and the molecular mechanisms underlying these effects were investigated.

COX 17 is an important factor for COX activity, and is responsible for the transition of $\mathrm{Cu}^{2+}$ to the $\mathrm{COX}$ subunit $(23,24)$. The results of the present study demonstrated that $1 \mathrm{mM}$ Hcy significantly decreased COX activity, and downregulated the expression of COX 17 in HUVECs. Further studies are required in order to elucidate the underlying mechanisms. Decreased COX activity levels may lead to the elevation of 
A

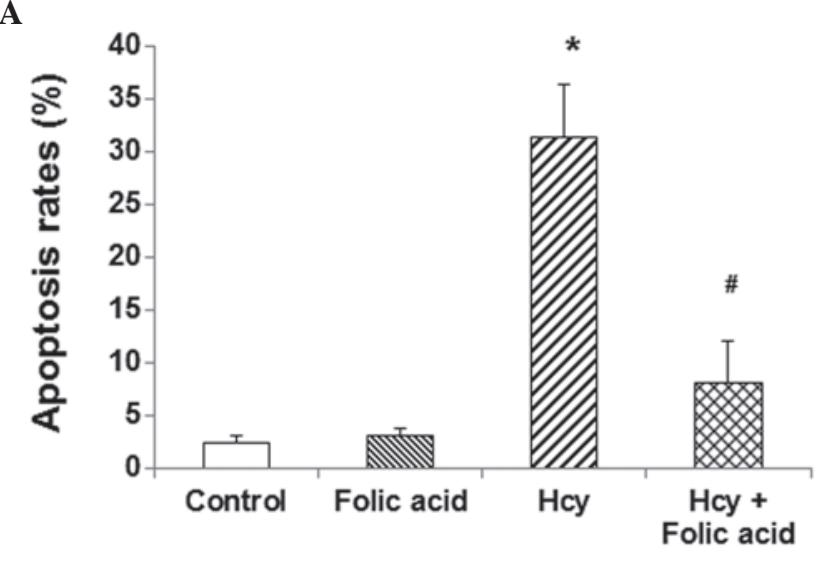

C

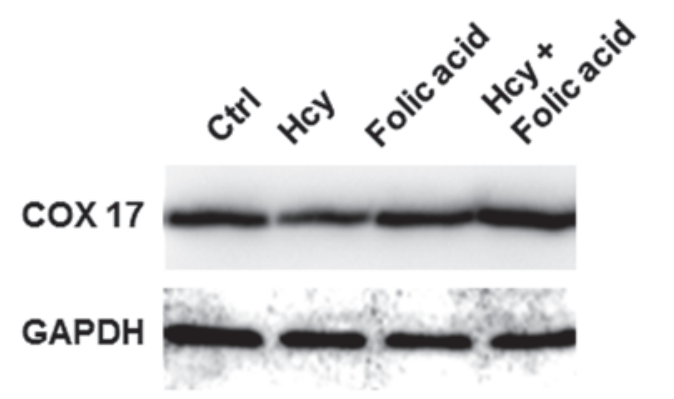

$\mathbf{E}$

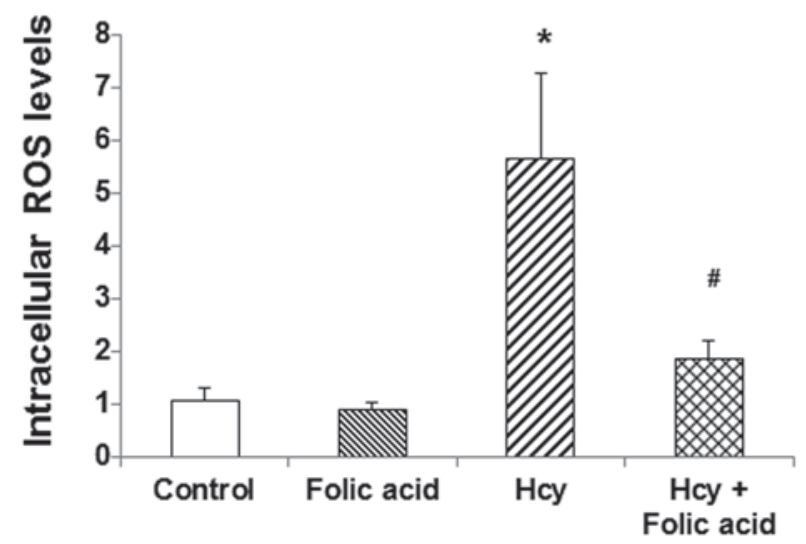

B

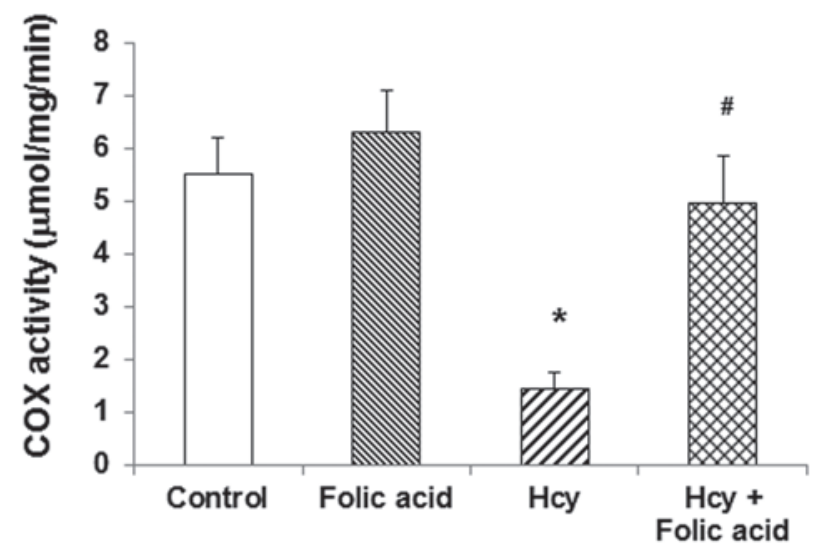

D

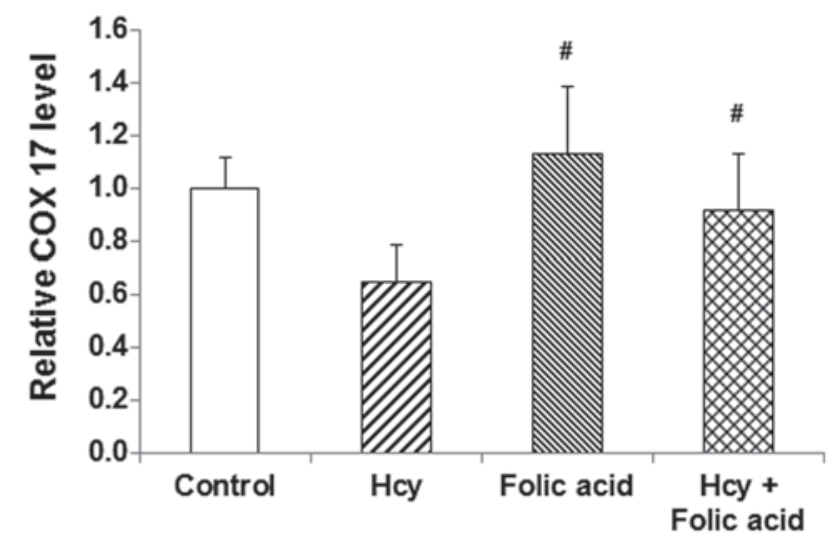

Figure 5. Folic acid alleviates the physiopathological changes induced by Hcy. HUVECs were treated with $1 \mathrm{mM}$ Hcy and/or $100 \mu \mathrm{mol} / 1$ folic acid for 24 h, and then the (A) apoptosis rate, the (B) COX activity levels, the (C and D) COX 17 expression levels and the (E) intracellular ROS levels were determined in these cells. ${ }^{*} \mathrm{P}<0.05$, vs. the control group; ${ }^{\#} \mathrm{P}<0.05$, vs. the Hcy group. ROS, reactive oxygen species; COX, cytochrome $c$ oxidase; Hcy, homocysteine; HUVECs, human umbilical vein endothelial cells.

intracellular ROS levels, further inducing apoptosis $(16,17)$. The results showed that $1 \mathrm{mM}$ Hcy significantly increased the intracellular ROS levels and the apoptosis rate in endothelial cells.

Within cells, Hcy may be methylated into methionine when catalyzed with methionine synthase (MS), which involves folic acid $(3,4)$. In the present study, folic acid was demonstrated to inhibit Hcy in endothelial cells. Moreover, treatment with folic acid treatment alleviated the physiopathological changes induced by Hcy in these cells.

In conclusion, the results demonstrated that Hcy inhibited COX activity and decreased the expression levels of COX 17, thereby increasing intracellular ROS levels, which eventually resulted in increased apoptosis rates in endothelial cells.
However, treatment with folic acid was able to alleviate the physiopathological changes induced by Hcy, restoring the COX activity and COX 17 expression levels, inhibiting intracellular ROS, and reducing the apoptosis rate in the endothelial cells. These findings suggest that the Hcy concentration in blood is important for the prevention of pulmonary embolism, which provides theoretical basis for the disease prevention in clinic. Further studies are required in order to explore the mechanisms underlying Hcy-induced COX activity decline.

\section{Acknowledgements}

The present study was supported by a grant from the National Natural Science Foundation (grant no. 81201494). 


\section{References}

1. de Miguel-Díez J, Jiménez-García R, López de Andrés A, Hernández-Barrera V, Carrasco-Garrido P, Monreal M, Jiménez D, Jara-Palomares L and Álvaro-Meca A: Analysis of environmental risk factors for pulmonary embolism: A case-crossover study (2001-2013). Eur J Intern Med 31: 55-61, 2016.

2. Heit JA: The epidemiology of venous thromboembolism in the community: Implications for prevention and management. J Thromb Thrombolysis 21: 23-29, 2006.

3. Tapson VF: Acute pulmonary embolism. N Engl J Med 358: 1037-1052, 2008.

4. Chen P, Poddar R, Tipa EV, Dibello PM, Moravec CD, Robinson K, Green R, Kruger WD, Garrow TA and Jacobsen DW: Homocysteine metabolism in cardiovascular cells and tissues: Implications for hyperhomocysteinemia and cardiovascular disease. Adv Enzyme Regul 39: 93-109, 1999.

5. Jeremy JY, Shukla N, Angelini GD, Day A, Wan IY, Talpahewa SP and Ascione R: Sustained increases of plasma homocysteine, copper and serum ceruloplasmin after coronary artery bypass grafting. Ann Thorac Surg 74: 1553-1557, 2002.

6. Karalezli A, Parlak ES, Kanbay A, Senturk A and Hasanoglu HC: Homocysteine and serum-lipid levels in pulmonary embolism. Clin Appl Thromb Hemost 17: E186-E189, 2011.

7. Köktürk N, Kanbay A, Aydoğdu M, Özyılmaz E, Bukan N and Ekim N: Hyperhomocysteinemia prevalence among patients with venous thromboembolism. Clin Appl Thromb Hemost 17: 487-493, 2011.

8. Okumus G, Kiyan E, Arseven O, Tabak L, Diz-Kucukkaya R, Unlucerci Y, Abaci N, Unaltuna NE and Issever H: Hereditary thrombophilic risk factors and venous thromboembolism in Istanbul, Turkey: The role in different clinical manifestations of venous thromboembolism. Clin Appl Thromb Hemost 14: $168-173,2008$.

9. Salles-Crawley II, Monkman JH, Ahnström J, Lane DA and Crawley JT: Vessel wall BAMBI contributes to hemostasis and thrombus stability. Blood 123: 2873-2881, 2014.

10. Ren M, Li R, Luo M, Chen N, Deng X, Yan K, Zeng M and Wu J: Endothelial cells but not platelets are the major source of Toll-like receptor 4 in the arterial thrombosis and tissue factor expression in mice. Am J Physiol Regul Integr Comp Physiol 307: R901-R907, 2014.

11. Mansoor MA, Bergmark C, Haswell SJ, Savage IF, Evans PH, Berge RK, Svardal AM and Kristensen O: Correlation between plasma total homocysteine and copper in patients with peripheral vascular disease. Clin Chem 46: 385-391, 2000.

12. Shukla N, Angelini GD and Jeremy JY: Interactive effects of homocysteine and copper on angiogenesis in porcine isolated saphenous vein. Ann Thorac Surg 84: 43-49, 2007.

13. Garnier A, Fortin D, Deloménie C, Momken I, Veksler V and Ventura-Clapier R: Depressed mitochondrial transcription factors and oxidative capacity in rat failing cardiac and skeletal muscles. J Physiol 551: 491-501, 2003.
14. Cawthon D, McNew R, Beers KW and Bottje WG: Evidence of mitochondrial dysfunction in broilers with pulmonary hypertension syndrome (Ascites): Effect of t-butyl hydroperoxide on hepatic mitochondrial function, glutathione and related thiols. Poult Sci 78: 114-124, 1999.

15. Cawthon D, Beers K and Bottje WG: Electron transport chain defect and inefficient respiration may underlie pulmonary hypertension syndrome (ascites)-associated mitochondrial dysfunction in broilers. Poult Sci 80: 474-484, 2001.

16. Suter M, Remé C, Grimm C, Wenzel A, Jäättela M, Esser P, Kociok N, Leist M and Richter C: Age-related macular degeneration. The lipofusion component N-retinyl-N-retinylidene ethanolamine detaches proapoptotic proteins from mitochondria and induces apoptosis in mammalian retinal pigment epithelial cells. J Biol Chem 275: 39625-39630, 2000.

17. Srinivasan S and Avadhani NG: Cytochrome $c$ oxidase dysfunction in oxidative stress. Free Radic Biol Med 53: $1252-1263,2012$.

18. Leadsham JE, Sanders G, Giannaki S, Bastow EL, Hutton R, Naeimi WR, Breitenbach M and Gourlay CW: Loss of cytochrome $c$ oxidase promotes RAS-dependent ROS production from the ER resident NADPH oxidase, Ynolp, in yeast. Cell Metab 18: 279-286, 2013.

19. Zou H, Li Y, Liu X and Wang X: An APAF-1. cytochrome $c$ multimeric complex is a functional apoptosome that activates procaspase-9. J Biol Chem 274: 11549-11556, 1999.

20. Hu Y, Benedict MA, Ding L and Núñez G: Role of cytochrome $c$ and dATP/ATP hydrolysis in Apaf-1-mediated caspase-9 activation and apoptosis. EMBO J 18: 3586-3595, 1999.

21. Saleh A, Srinivasula SM, Acharya S, Fishel R and Alnemri ES: Cytochrome c and dATP-mediated oligomerization of Apaf-1 is a prerequisite for procaspase-9 activation. J Biol Chem 274: 17941-17945, 1999.

22. Hassanin IM, Shahin AY, Badawy MS and Karam K: D-dimer testing versus multislice computed tomography in the diagnosis of postpartum pulmonary embolism in symptomatic high-risk women. Int J Gynaecol Obstet 115: 200-201, 2011.

23. Glerum DM, Shtanko A and Tzagoloff A: Characterization of COX17, a yeast gene involved in copper metabolism and assembly of cytochrome oxidase. J Biol Chem 271: 14504-14509, 1996.

24. Takahashi Y, Kako K, Kashiwabara S, Takehara A, Inada Y, Arai H, Nakada K, Kodama H, Hayashi J, Baba T and Munekata E: Mammalian copper chaperone Cox17p has an essential role in activation of cytochrome $\mathrm{C}$ oxidase and embryonic development. Mol Cell Biol 22: 7614-7621, 2002. 